\title{
¿Qué es una resolución judicial? Un breve estudio analítico para el derecho procesal civil peruano(")(")
}

\section{What is a judicial decision? A brief analytic study for Peruvian civil procedural law}

\author{
Renzo Cavani ${ }^{(* *)}$ \\ Pontificia Universidad Católica del Perú
}

\begin{abstract}
Resumen: En el presente trabajo se exploran dos conceptos jurídicos básicos, resolución judicial y decisión, a la luz de la regulación del Código Procesal Civil peruano de 1993 (CPC). Este análisis se realiza a partir de un enfoque analítico-dogmático, buscando demostrar que un adecuado trabajo con dichos conceptos es decisivo para resolver problemas prácticos, sobre todo en el ámbito de la impugnación.
\end{abstract}

Palabras clave: Resolución judicial - Decisión - Sentencia - Recursos Procedencia - Mérito

\begin{abstract}
In this essay two basic legal concepts, judicial decision and adjudication, are explored in the light of the discipline of Peruvian Civil Procedure Code of 1993 (CPC). This analysis is made from an analyticdogmatic perspective, aiming to show that an adequate use of those concepts is decisive to solve practical problems, foremost in the field of the appeal.
\end{abstract}

$\left(^{*}\right) \quad$ Nota del editor: Este artículo fue recibido el 10 de noviembre de 2017 y su publicación fue aprobada el 25 de noviembre de 2017.

${ }^{(* *}$ El autor agradece a Stefan Espejo, miembro ordinario de la Asociación IUS ET VERITAS y Director de la Comisión de Investigación, quien fuere su alumno en el curso Revisión e impugnación judicial de la PUCP, por la lectura del esbozo que dio origen a este texto y, por supuesto, por sus punzantes comentarios, los cuales llevaron a que sea notablemente ampliado.

${ }^{(* *}$ ) Profesor de derecho procesal civil en pregrado y postgrado en la Pontificia Universidad Católica del Perú (PUCP) y en Universidad de Piura (UdeP). Profesor en la Academia de la Magistratura (AMAG). Investigador en la Cátedra de Cultura Jurídica de la Universitat de Girona (UdG). Doctorando en la UdG (área de filosofía del derecho). Magíster en Derecho por la Universidade Federal do Rio Grande do Sul (UFRGS). Abogado por la Universidad de Lima. Miembro de la Comisión Revisora del Código Procesal Civil convocada por el Ministerio de Justicia y Derechos Humanos (2016-2017). Miembro del Instituto Brasileiro de Direito Processual (IBDP) y de la Associação Brasileira de Direito Processual (ABDPro). Correo electrónico: prof.renzo.cavani@gmail.com 


\section{¿Qué es una resolución judicial? Un breve estudio analítico para el derecho procesal civil peruano What is a judicial decision? A brief analytic study for Peruvian civil procedural law}

Keywords: Judicial Decision - Adjudication - Ruling - Appeal Admissibility - Merits

Sumario: 1. Premisa_2. Resolución-documento y resoluciónacto_3. Resoluciones y contenido decisorio: juicio de procedenciay juicio de mérito_4. Resolución, decisión, extremos e impugnación: algunas precisiones conceptuales_5. Las resoluciones-acto en el proceso civil peruano: decretos, sentencias y autos_5.1. Decretos_5.2. Sentencia. 5.3. Autos_6. Resoluciones dentro de una resolución_7. Conclusiones.

\section{Premisa}

Existen algunos temas cuya riqueza, y complejidad, teórica suele pasar desapercibida por los estudiosos del Derecho Procesal en nuestro país. Se incurre, pues, en lugares comunes (definiciones, clasificaciones), y la práctica no encuentra respuestas sólidas para enfrentar diversos problemas que suceden con no poca frecuencia. Dos de esos conceptos, que a primera vista parecen bastante simples, son la resolución judicial y la decisión.

La propuesta de este breve trabajo es explorar tales conceptos desde un enfoque analítico que sirva de base para la redefinición dogmático-conceptual (es decir, con una especial preocupación por el derecho positivo) para que, finalmente, sea de utilidad a fin de resolver algunos problemas prácticos que pueden presentarse

\section{Resolución-documento y resolución-acto}

La primera idea que viene a la cabeza cuando se habla de resolución judicial es la forma cómo el juez se comunica con las partes. No obstante, estamos ante un término polisémico. Es posible entender resolución de dos formas diversas: a) Resolución como documento. Se hace referencia a un conjunto de enunciados normativos expedido por un órgano jurisdiccional. Por ejemplo: Resolución Nro 4; en la resolución impugnada se decidió no admitir el recurso del demandante, etcétera. La división entre parte expositiva, considerativa y dispositiva, pues, corresponde a la resolución-documento.

b) Resolución como acto procesal. Un acto procesal es, fundamentalmente, un hecho jurídico voluntario practicado en el proceso y con eficacia para el mismo ${ }^{(1)}$. Dado que es realizado por un órgano juzgador se trata de un acto procesal del juez (aquí hablamos del juez, pero también puede tratarse, por cierto, de ser un árbitro o de la Administración Pública). No todo acto del juez es una resolución: este también puede realizar actos de naturaleza administrativa, como sería el caso de llamar la atención a su personal, emitir oficios (esto es, comunicación con otros jueces, autoridades públicas o privadas, según el artículo 148, del Código Procesal Civil [en adelante, "CPC"]) o librar exhortos (comunicación con otras autoridades para que se realice algún acto determinado, artículo 151 del CPC). Los actos del juez que sí son resoluciones pueden contener una decisión o no. Esto lo explicaré en el siguiente ítem.

El ar tículo 120 del CPC dice: Los actos procesales a través de los cuales se impulsa o se decide al interior del proceso o se

(1) Las complejidades de definir el concepto acto procesal no son pocas. Además de la doctrina clásica (por ejemplo: Pannain, 1933; Carnelutti, 1938; Conso, 1955; Redenti, 1959), también es prolífico es recurrir a la doctrina que teoriza sobre el hecho jurídico como una pretensión transordinamental más amplia (aquí destaca Pontes De Miranda, 1970; Mello: 2014 ; 163 y siguientes; Calmon De Passos, 2009: 15 y siguientes) y, de allí, a la doctrina contemporánea que viene debatiendo sobre el asunto. Por ejemplo: Almeida, 2015; Ataíde Jr., 2015; Cabral, 2016; Costa, 2017; Didier Jr. y Nogueira, 2011; Nogueira, 2016, así como los diversos textos que componen dos obras colectivas: Cabral y Nogueira, 2017, y Nogueira y Cavani, 2015. Valga la oportunidad para indicar que mi pensamiento ha cambiado respecto a la exposición que hiciera en alguna publicación anterior, Véase Cavani, 2014: 165 y siguientes. 
Renzo Cavani

pone fin a este, pueden ser decretos, autos y sentencias (énfasis agregado). Nótese bien: el CPC entiende que estos tres tipos de resoluciones son actos procesales. Con ello, queda demostrada la diferenciación hecha anteriormente: la resolución-documento no se confunde con la resolución-acto.

Esto no debe extrañar, porque la diferencia entre resolucióndocumento y resolución-acto es la misma, por ejemplo, que la diferencia entre contrato-documento y contrato-acto, y también entre demanda-documento y demanda-acto. Esto puede llevar a intuir, entre otras cosas, que, dentro de una resolución, puede haber varias resoluciones; es decir, en un documento puede haber varios actos. Esto no parece ser nada extraño, por supuesto, pero las consecuencias prácticas son muy importantes puesto que, dependiendo de qué resolución se trate, habrá un medio impugnatorio (recurso) diferente. Esto se verá más adelante.

\section{Resoluciones y contenido decisorio: juicio de procedencia y juicio de mérito}

A partir de la diferenciación realizada, podemos clasificar las resoluciones-acto en dos tipos:

a) Resoluciones sin contenido decisorio.

b) Resoluciones con contenido decisorio.

¿A qué se alude con contenido decisorio? Veamos. El juez, mediante una resolución (acto procesal), suele dar respuesta a lo que las partes le piden (salvo aquellos casos en donde actúa de oficio). No obstante, no todos los pedidos son iguales. Hay pedidos que importan una decisión. Sin perjuicio de lo que se dirá más adelante, aquí hablamos de decisión en sentido estricto, esto es, un juicio que resuelve una cuestión. Una cuestión es cualquier punto de hecho o de derecho que surja a lo largo del procedimiento(2). Si observamos bien la dicción del artículo 120, puede apreciarse una diferencia entre el acto que impulsa el proceso, el acto que decide al interior del proceso y el acto que pone fin a este. El acto que impulsa se diferencia de los actos que deciden algo, sea al interior del proceso, sea poniéndole fin. Así, los dos últimos implican una decisión; el primero no. El propio CPC, por tanto, reconocería que existen resoluciones sin contenido decisorio (porque no hay decisión) y resoluciones con contenido decisorio.
Hast a este punto, portanto, tenemos tres $f$ iguras que no deben confundirse: resolución-documento, resolución-acto y decisión. La resolución-acto está contenida en la resolución-documento, mientras que la decisión, entendida como juicio, puede componer o no la resolución-acto (dado que esta puede no tener contenido decisorio).

El juicio que resuelve una cuestión puede ser de procedencia o de mérito. El juicio es de procedencia cuando consiste en un examen de los requisitos del pedido. El juicio es de mérito cuando consiste en un examen respecto del contenido del pedido (dando o no la razón a la parte que pide).

El juicio de procedencia puede ser positivo o negativo.

a) Si se da un juicio positivo es porque se constató que los requisitos del pedido están adecuadamente configurados y, por tanto, que es posible entrar al juicio de mérito.

b) Si se da un juicio negativo es porque se constató que los requisitos del pedido no están adecuadamente configurados y, por tanto, que no es posible entrar al juicio de mérito. El juicio negativo puede ser definitivo o provisional.

b.1. En el juic io def initivo, el pedido es rec ha $z$ ado. Aquí se $c$ onst at a la imposibilidad de subsanar el defecto o la omisión de uno o más requisitos. Esto es lo que ocurre con la improcedencia de la demanda o de cualquier otro pedido (por ejemplo: medios probatorios extemporáneos, nulidad, excepciones, cuestiones probatorias, etcétera).

(2) Cónfer Didier Jr., 2015: 432. En nuestra doctrina, Cónfer Monroy Palacios, 2005: 190 y siguientes. 


\section{¿Qué es una resolución judicial? Un breve estudio analítico para el derecho procesal civil peruano What is a judicial decision? A brief analytic study for Peruvian civil procedural law}

b.2. En el juicio provisional, el pedido aún puede ser subsanado(3). Aquí se constata la posibilidad de subsanar el defecto o la omisión de uno o más requisitos; de allí que se conceda un plazo. Esto es lo que ocurre con la inadmisibilidad de la demanda o de un recurso en caso se presente un arancel diminuto: es necesario que se subsane este defecto para que el trámite principal continúe 0 , en el segundo caso, para pueda haber un juicio sobre el mérito recursal.

Por su parte, el juicio de mérito también puede ser positivo o negativo. Si es positivo, se estima (se otorga, se da la razón) lo que la parte pidió (aquí es donde entra el término fundado); si es un juicio negativo, se desestima (no se otorga, no se da la razón) lo que la parte pidió (aquí es donde entra a tallar el término infundado).

De lo que se trata es, pues, de identificar que decidir significa, rigurosamente, un juicio de procedencia o de mérito respecto de una cuestión, que, normalmente, es formulada en un pedido (demanda, recurso, etcétera) ${ }^{(4)}$.

\section{Resolución, decisión, extremos e impugnación: algunas precisiones conceptuales}

En este punto toca realizar algunas precisiones concernientes a vincular el tema expuesto con el ámbito de la impugnación (concretamente, la impugnación recursal). Como se anticipó, esto podría dar paso, de hecho, a ulteriores estudios, siempre desde una perspectiva analítica, sobre la teoría de la resolución judicial

Pues bien, ¿qué es lo que realmente se impugna? ¿Será la resolución-documento, la resolución-acto o la decisión? Para ello, es importante constatar que en el recurso se exterioriza una pretensión recursa(15), que, como pretensión procesal que es, se compone de una causa de pedir recursal y de un pedido recursal. La pretensión recursal está vinculada al mérito recursal. La causa de pedir es la razón por la que se pide y está compuesta por hechos jurídicos. Por ello, en la causa de pedir recursal se alega el hecho jurídico que da sustento a una de dos consecuencias: el error in iudicando (vicio) y el error in procedendo (o, simplemente, error). Por su parte, el pedido es la manifestación concreta de lo que se pide. El pedido recursal puede consistir, por tanto, en una nulidad (alegando un vicio) o en una revocación (alegando un error) ${ }^{(6)}$.

Pues bien, a partir del lenguaje práctico se suele entender que el recurso se dirige contra una resolución judicial. Así es como se habla de apelar el auto/sentencia, interponer un recurso contra la resolución No. 13, solicitar que se revoque la resolución impugnada. No obstante, si, como se ha dicho, una resolución-documento es apenas un conjunto de textos y enunciados, esta no podría ser realmente el objeto de impugnación.

¿Sería entonces la resolución-acto? En este punto es importante advertir que un acto jurídico (como es el caso de un acto del juez), como un hecho jurídico voluntario que tiene como elemento nuclear la exteriorización de voluntad(7), sí es susceptible de anularse, impugnarse o revocarse, ya que, en general, serían formas de pérdida de eficacia.

Pero es menester profundizar el análisis. Desde una perspectiva horizontal es posible

(3) No se trata, como defiende Monroy Palacios (2005: 192-193), una declaración provisional de invalidez. Las críticas pueden encontrarse en Cavani, 2014: 524 y siguientes.

(4) Digo normalmente, porque también puede ser suscitada de oficio.

(5) Un término que ya ha calado en la práctica forense y judicial es «pretensión impugnatoria» que, inclusive, está expresamente reconocido en el artículo 366 del CPC, aunque en el capítulo que versa sobre apelación.

(6) Todo esto conforme, en gran medida, a Didier Jr. y Carneiro da Cunha, 2016: 105 y siguientes, esp. 134 y siguientes, con base en las lecciones de José Carlos Barbosa Moreira.

(7) Ampliamente, incidiendo en la diferenciación entre acto jurídico en sentido estricto y negocio jurídico, Cónfer Nogueira, 2016: 111 y siguientes, esp. 121 y siguientes; Costa, 2017: 38 y siguientes. 
Renzo Cavani

diseccionar aquello que, en una resolución judicial, puede ser impugnado por la parte. Trabajemos con el ejemplo que propone Ariano: a) se demanda 100 más intereses desde constitución en mora; b) la sentencia otorga 90 más intereses, pero estos deben ser computados desde la interposición de la demanda; c) el demandante apela únicamente el cómputo de los intereses, cuestionando que sería a partir de la constitución en mora (2015, 162 y siguientes). Aquí, cuando menos, tenemos tres porciones o fragmentos de la sentencia (resolución-acto) que han sido enunciados en la parte dispositiva: (i) capital, (ii) intereses y (iii) el momento desde que se computan. En este ejemplo, lo que el demandante estaría apelando es solamente (iii), por lo que la extensión del recurso determina que el juez de apelación no pueda pronunciarse respecto de (i) ni de (ii) ${ }^{(8)}$.

Estas porciones o fragmentos se conocen como extremos. Un extremo es una deliberación específica del juez dotada de presupuestos propios(9), que, si bien conforman la resolución-acto, poseen autonomía propia. La existencia de mayor o menor cantidad de extremos se debe "al mayor o menor alcance y complejidad de las cuestiones suscitadas y debatidas" (Araken de Assis 2015, 900). Pero, aquí lo importante: el extremo de una resolución-acto no puede ser confundido con una parte de la resolución-documento. En efecto, la decisión respecto del cómputo de los intereses del ejemplo anterior es algo diverso a la parte dispositiva de la sentencia donde dicha decisión está materializada.

Existen tantos extremos cuantos pedidos (pretensiones) se hayan formulado, pero, a su vez, un extremo puede dividirse en otros extremos (o subextremos) dependiendo de si dicho pedido es descomponible; esto es, si es que versan sobre bienes que pueden ser objeto de recuento, medida, peso o cualquier otro tipo de cuantificación (Didier Jr, Braga y Olivera 2015, 352 y siguientes). Por ejemplo, si una sentencia declara fundada en parte la demanda, ordenando pagar 20 mil de los 50 mil que se pidió, entonces un subextremo será los 20 mil y otro subextremo será los 30 mil restantes. Asimismo, en una resolución puede emitirse un juicio de procedencia y, también, un juicio de mérito. En dicho caso se puede identificar dos extremos: el extremo sobre cuestiones procesales y el extremo sobre el mérito (Didier Jr., Braga y Olivera 2015, 353). Finalmente, en la sentencia y algunos autos, además de todos los extremos identificables, también suele tener un extremo sobre las costas y costos.

Como se ha dicho, las resoluciones judiciales (entendidas como documento) poseen tres partes: expositiva, considerativa y dispositiva. En la expositiva se recuenta los antecedentes que justifican la dación de la resolución; en la considerativa se desarrollan los fundamentos y argumentos; en la dispositiva, finalmente, se resuelve lo pertinente, mediante declaraciones u órdenes (es lo que se conoce como fallo) 0 , en palabras de Chiassoni, enunciaciones judiciales performativas $(2007,17)$.

Bien vistas las cosas, un extremo no es otra cosa que una decisión, esto es, como ya se manifestó, un juicio que resuelve una cuestión. Pero, con mayor precisión, también es posible entender la decisión (judicial) como una conclusión que es "confirmada por el razonamiento justificativo a partir de un conjunto de premisas normativas y no normativas (factuales, interpretativas, calificativas)" (Chiassoni 2007, 17; Guastini 2011, 238). Aquí, como puede intuirse, desempeña un rol fundamental la justificación interna y externa de la decisión judicia/(10).

Por consiguiente, un extremo no se circunscribe a la norma concreta enunciada en la parte dispositiva; más bien los extremos se identifican a partir de aquello que fuera resuelto en la par te dispositiva, con su respectiva fundamentación, precisamente porque la decisión es el punto de llegada de un razonamiento jurídico, conducido este

(8) Como puede intuirse, la extensión del recurso tiene que ver con lo que se suele denominar efecto devolutivo de la apelación.

(9) Véase Araken de Asis (2015:901), siguiendo de cerca la lección de Dinamarco, quien emplea el término capítulos de sentencia.

(10) Sobre el asunto, de forma resumida, Cónfer Cavani, 2015: 362 y siguientes. 


\section{¿Qué es una resolución judicial? Un breve estudio analítico para el derecho procesal civil peruano What is a judicial decision? A brief analytic study for Peruvian civil procedural law}

mediante actividades lógico-discursivas que componen lo que se conoce como argumentación jurídica(11).

Con ello, la pregunta ya formulada al inicio de este ítem (¿Cuál es el objeto de la impugnación?) es posible que sea respondida de la siguiente manera: aquello que se impugna sí es la resolución-acto, pero, más concretamente, la decisión. La pretensión recursal formulada en un recurso se dirige específicamente contra la decisión, por ejemplo, de condenar a pagar una suma de dinero o de declarar la existencia del derecho de propiedad alegado. Se impugna la conclusión del razonamiento, pasando a cuestionarse sus pasos (o inferencias). De ahí que sea absolutamente correcto decir que se cuestiona/recurre/impugna uno o más extremos de una resolución judicial.

Corresponde ahora aterrizar un poco más a fin de demostrar las consecuencias prácticas de todo lo dicho hasta ahora.

\section{Las resoluciones-acto en el proceso civil peruano: decretos, sentencias y autos}

En el proceso civil peruano (y también en otros procesos de nuestro ordenamiento), la resolución sin contenido decisorio es el decreto, mientras que las resoluciones con contenido decisorio son las sentencias y los autos ${ }^{(12)}$. Por consiguiente, los decretos son resoluciones en donde propiamente no se decide, esto es, no hay pronunciamiento sobre el derecho discutido o una cuestión suscitada en el transcurso del proceso. Ello sí ocurre en el caso de los autos y las sentencias, diferenciándose ambas resoluciones, a su vez, según aquella cuestión que es resuelta. Más adelante veremos qué es lo que contiene el decreto si es que, como se ha dicho, no habría una decisión.

Pasemos a caracterizar cada una de las resoluciones judiciales.

\subsection{Decretos}

El artículo 121, inciso 1 del CPC, señala:

\begin{abstract}
"Mediante los decretos se impulsa el desarrollo del proceso, disponiendo actos procesales de simple trámite".
\end{abstract}

Parecería que el texto equipara el impulso del proceso con acto de simple trámite, o, más precisamente, que este último siempre sería un acto de impulso. Ello no es del todo correcto: hay actos de trámite que no son, rigurosamente, actos de impulso. La respuesta la da el propio CPC cuando regula el abandono.

Esta f igura consiste en una sanción al demandante que, en la tramitación del proceso en primera instancia, no realiza ningún acto de impulso (ver artículos 346 y siguientes del CPC) $)^{(13)}$. Pero, es el artículo 348 inciso 3 del CPC el que da mayores luces sobre esta última figura:

"No se consideran actos de impulso procesal aquellos que no tienen por propósito activar el proceso, tales como la designación de nuevo domicilio, pedido de copias, apersonamiento de nuevo apoderado y otros análogos".

Así, designar nuevo domicilio procesal, pedir copias, apersonar nuevo apoderado o abogados son pedidos que, evidentemente, requieren respuesta por parte del juez. Pero esta respuesta no es una decisión tal como se ha definido: es un acto de simple trámite. De ahí que la respuesta del juez será muy sucinta:

(11) Cónfer Atienza, 2013: 109 y siguientes; Zavaleta, 2014: 39 y siguientes.

(12) En doctrina se le conocen más usualmente bajo el nombre de resoluciones interlocutorias o, más antiguamente, sentencias interlocutorias.

(13) No debe olvidarse que el juez está obligado a impulsar el proceso por sí mismo (art. II, §2, CPC), salvo los casos expresamente señalados en el propio CPC. Esto podría generar una contradicción con el propio abandono, porque ahí no se dice en qué circunstancia es la parte que debe realizar determinada actuación para que no se configure el abandono. 
Renzo Cavani

Expídanse las copias certificadas, Téngase por apersonado al letrado que se indica, etcétera.

Es importante diferenciar entre acto de impulso como acto procesal de parte, el cual contendrá un pedido de impulso, y acto de impulso como acto procesal del juez, el cual constituiría estrictamente un decreto. Así pues, el pedido de impulso el proceso busca activarlo, esto es, que prosiga con su trámite de acuerdo al procedimiento previsto y a los actos que el juez debe realizar para que se encamine a su conclusión (eso es exactamente lo que se exige para que no se declare el abandono). Pero nótese que el pedido de impulso puede recibir diversas respuestas por parte del juez: desde un simple decreto hasta una senda resolución con contenido decisorio. Para efectos del abandono, lo que interesa no es tanto la respuesta del juez, sino si el pedido de la parte conduce o no a un impulso o activación del proceso. Así pues, pedidos de impulso, por ejemplo, pueden ser: solicitar al juez que expida sentencia, que reprograme una diligencia, etcétera.

Tenemos, por tanto, el contenido de los decretos puede ser de dos tipos:

a) De impulso del proceso: Son aquellos que disponen la continuación del proceso. Ejemplos: correr traslado de algún pedido previo a la decisión; declarar que una resolución ha quedado consentida; disponer que el expediente sea llevado a despacho para resolver, etcétera.

b) De mero trámite: Es una respuesta del juez que no dispone la continuación del proceso sino simplemente atender a un pedido simple de una parte (si lo hubiere), que no involucra una decisión. Ejemplos: expedición de copias certificadas (artículo 139 del CPC); expedición de copias para el Ministerio Público para que evalúe si ejercita la acción penal (artículos 38, inciso 2; 441, inciso 1; 538, inciso1; 564, inciso 2; 624, inciso 1 ; todos del CPC) o para el órgano de control (artículo 140 del CPC); tener presente un escrito para mejor resolver; tener por apersonado a un abogado o apoderado, etcétera. Véase que ninguna de estas resoluciones conduce a la conclusión del proceso ni tampoco contribuye con su prosecución.

En este punto, a par tir de lo defendido en los ítems precedentes, cabría preguntarse lo siguiente: si es que el objeto de la impugnación sería concretamente la decisión, ¿qué ocurre con la impugnación los decretos? Cabe decir que este punto ha sido muy poco explorado en doctrina.

En los decretos el juez no tiene el deber de motivar porque dicha resolución no posee contenido decisorio. Si no se decide, entonces no se requiere motivar. Por ello es que el artículo 12 de la Ley Orgánica del Poder Judicial (en siglas, LOPJ) es bastante expresiva al respecto: "Todas las resoluciones, con exclusión de las de mero trámite, son motivadas, bajo responsabilidad". Si bien analógicamente podemos extender las resoluciones de mero trámite a las de impulso procesal, el punto esencial aquí es que los decretos no se motivan.

¿Querría decir ello que el decreto, por no c ontener decisión alguna, no sería impugnable? La respuesta es negativa, porque el propio CPC permite que el decreto sea atacado mediante el recurso de reposición, exigiendo al recurrente, como en el caso de los otros recursos como la apelación o casación, que fundamente su pretensión impugnatoria (precisando el agravio y el error).

Como se ha dicho, la impugnación sí se dirige contra la resolución-acto, como sería el caso del decreto; pero aquí se puede advertir que el recurso de reposición tendría una finalidad un tanto particular: al no haber motivación en la resolución impugnada, el recurrente exige al juez que analice el decreto, forzándolo a dar razones y, esta vez sí, a decidir si es que dicho decreto está de conformidad con la ley o si, en caso no lo estuviese, sea revocado. La resolución que se pronuncia respecto del recurso de reposición es, evidentemente, una resolución con contenido decisorio, específicamente un auto (ver infra).

Nótese que si el juez resuelve el mérito recursal de la reposición, el auto que emita pasará a sustituir la resolución impugnada. En 


\section{¿Qué es una resolución judicial? Un breve estudio analítico para el derecho procesal civil peruano What is a judicial decision? A brief analytic study for Peruvian civil procedural law}

este caso, por tanto, aunque la legislación sobre los medios impugnatorios del CPC no realiza un tratamiento diferenciado, el recurso de reposición sería una impugnación sui generis: una que no cuestiona propiamente una decisión, sino, en realidad, lo que podría denominarse un pronunciamiento meramente de ordenación.

Un pronunciamiento meramente de ordenación presupone la emisión de una mera orden, cuya característica principal es que no está justificada. De hecho, sí hay un juicio subsuntivo (encuadramiento del hecho en una norma procesal) por detrás de este pronunciamiento, pues, de lo contrario, no habría aplicación del derecho. La particularidad es que este juicio no ha sido expresado porque el juez no está obligado a motivar. Pues bien, si es que la justificación exige no precisamente dar cuenta de los motivos sino, realmente, explicitar las razones que permiten considerar una decisión como aceptable o racional (Atienza 2013, 114-15), en un decreto no hay manera de determinar si es que existió o no una adecuada justificación y, por tanto, si se realizó bien o mal dicho juicio subsuntivo. En efecto, cuando el juez dice "Téngase presente", "Tráigase los autos a despacho para resolver" o "Téngase por apersonado al letrado que se indica", ni siquiera suele invocar el artículo que contiene la norma procesal pertinente y, si lo invoca, no justifica porqué sería dicha norma la aplicable: simplemente emite una mera orden.

Asimismo, no debe olvidarse que, por definición, una decisión resuelve una cuestión. Esta particularidad es importante, puesto que pedir el apersonamiento de un abogado o solicitar tener presente el cambio de domicilio no constituye ningún punto fáctico o jurídico que incida sobre el derecho discutido ni sobre algún punto fáctico o jurídico en la tramitación del proceso.

A partir de esta constatación bien podría argumentarse, desde una perspectiva estrictamente pragmática, que al recurrente que interpone un recurso de reposición no debería exigírsele la misma rigurosidad en el cumplimiento de los requisitos de admisibilidad y procedencia que en el caso, por ejemplo, de un recurso de apelación o casación. En efecto, si este recurso busca forzar al juez a motivar, mediante una auténtica decisión, si es que el decreto es o no correcto, entonces al recurrente debería bastarle, de forma muy superficial, expresar cuál debió haber sido el sentido del decreto y en base a qué norma debió ser así.
Por ejemplo, si se rechaza un pedido de copias certificadas, invocar la norma que lo autoriza y que se expidan; si se presenta un escrito y se indica téngase presente al momento de resolver, omitiendo correr traslado por un plazo determinado, indicar que se debió realizar dicha conducta teniendo en cuenta la naturaleza de lo solicitado en el escrito; si se tiene por apersonado a uno y no a los dos abogados indicados en el escrito de apersonamiento, señalar que debería tenerse como apersonado también al otro.

\subsection{Sentencia}

El artículo 121 inciso 3 del CPC señala:

\begin{abstract}
"Mediante la sentencia el juez pone fin a la instancia o al proceso en definitiva, pronunciándose en decisión expresa, precisa y motivada sobre la cuestión controvertida declarando el derecho de las partes, o excepcionalmente sobre la validez de la relación procesal".
\end{abstract}

La sentencia es una resolución judicial con contenido decisorio en donde confluyen dos elementos: a) poner fin a la instancia o al proceso y $b$ ) un pronunciamiento sobre el fondo. Por fondo, en este contexto, debe entenderse un juicio de mérito sobre la pretensión formulada en la demanda (esto es, declararla fundada, fundada en parte o infundada). Nótese, además, que, en el ámbito de la impugnación de sentencia, un juez emite sentencia pronunciándose sobre la pretensión recursal (fundado o infundado el recurso) y, a continuación, sobre la pretensión contenida en la demanda (improcedente, infundada o fundada la demanda). La cuestión controvertida, por tanto, no es otra cosa que la res in iudicium deducta, la cuestión de mérito principal o, también, el objeto litigioso del proceso ${ }^{(14)}$.

(14) Sobre el asunto, ampliamente, Cónfer Tucci, 2009: 95 y siguientes; Domit, 2016. 
Renzo Cavani

Una lectura paralela del CPC podría llevar a concluir que en la sentencia el juez también puede emitir una decisión sobre la validez de relación procesal, esto es, un pronunciamiento sobre la procedencia de la demanda y, de ser el caso, anulando total o parcialmente el procedimiento (la así llamada sentencia inhibitoria)(15). No obstante, esta interpretación conduce a una incoherencia sistemática, ya que todo pronunciamiento que implique un juicio de procedencia de la demanda, sea liminar (artículo 427 del CPC), sea respecto de una excepción (artículos 451 y 465 incisos 2 y 3, todos del CPC), importa una decisión que no resuelve el fondo; o, para ser más precisos, aun cuando analice la pretensión, que por disposición legal no tenga como consecuencia la cosa juzgada y sí la nulidad de todo lo actuado, improcedencia de la demanda y conclusión del proceso(16).

En otras palabras, no tendría sentido que una sentencia pueda contener un juicio de mérito sobre la pretensión y, a la vez, un juicio de procedencia sobre la demanda solamente por el hecho de dictarse al final del procedimiento; mientras que todas las demás resoluciones que contengan un juicio de procedencia respecto de la demanda que sean emitidas en cualquier otro momento del iter procesal no califiquen como sentencia y sí, más bien, como auto. En efecto, si es que una resolución que declara la improcedencia de la demanda tiene las mismas consecuencias, ¿por qué habría alguna diferencia según la oportunidad en que se adopte?

En mi opinión, lo que el legislador quiso decir, en realidad, es que al momento de sentenciar, o, mejor, en lugar de emitir sentencia, el juez puede emitir un auto, decidiendo sobre la validez de la relación procesal. Este entendimiento, inclusive, se muestra más armónico con los artículos 321 y 322 del CPC: cuando el juez se pronuncia sobre la validez de la relación procesal, según esta lógica, no resuelve el fondo o mérito del proceso; sí lo hace, en cambio, cuando sentencia, declarando fundada o infundada la demanda.

Esclarecido este asunto, corresponde destacar que, desde una perspectiva temporal, no solo existe sentencia cuando se llega al final del procedimiento (de primera, segunda o tercera instancia): también hay otras sentencias producto de diversas formas de conclusión del proceso que comparten su naturaleza de ponerle fin al proceso mediante una declaración sobre el mérito. Veamos:

a) Conciliación judicial. La conciliación es un negocio jurídic o material $c$ on efectos procesales ${ }^{(17)}$ : el hecho que se dé en el contexto de un proceso no resta su naturaleza de contrato o negocio jurídico bilateral. Si las partes concilian, el juez examina si es que el derecho es disponible (artículo 325 del CPC) y acepta la propuesta conciliatoria y declara la conclusión del proceso (artículo 327 del CPC). Esta aceptación se denomina homologación. Cuando el juez, mediante resolución homologatoria, acepta la conciliación, decide respecto del pedido de conclusión del proceso, pero también incluye un pronunciamiento sobre la pretensión (artículo 322, inciso 2 del CPC). Hay, pues, una declaración sobre el fondo. Tal declaración consiste en constatar que las partes han conciliado y que el derecho material en discusión queda reconocido

(15) Es lo que defiende, por ejemplo, Ariano, 2015: 194 y 212, nota 1, refiriéndose a ella como sentencia absolutoria de instancia.

(16) Sin perjuicio de lo que se argumenta en el texto principal, existen elementos que, indudablemente, componen el mérito del proceso y que, por tanto, se requiere analizar la pretensión y los medios de prueba, pero que nuestro CPC les ha dado como consecuencia la improcedencia de la demanda, nulidad de todo lo actuado. O sea, nuestro legislador entendió que se trata realmente de un análisis sobre la validez de la relación procesal, como si fuese, por ejemplo, competencia, capacidad procesal, representación procesal, etc. Tales elementos son, por ejemplo, la legitimidad para obrar, caducidad, prescripción, cosa juzgada, transacción, conciliación, desistimiento, etc. Todos ellos requieren que el juez entre efectivamente a analizar la relación material (pretensión) a fin de determinar qué fue lo que sucedió con el derecho que es reclamado por el demandante. Cónfer Cavani, 2014: 509.

(17) Cónfer Denti, 1965: 469-470; Costa, 2017: 24 y siguientes. 


\section{¿Qué es una resolución judicial? Un breve estudio analítico para el derecho procesal civil peruano What is a judicial decision? A brief analytic study for Peruvian civil procedural law}

en los términos del acuerdo. Por ello es que el artículo 328 del CPC, dice: "La conciliación surte el mismo efecto que la sentencia que tiene la autoridad de cosa juzgada". Cuando se dice que surte el mismo efecto no se refiere a que la resolución homologatoria debe tomarse como si fuera una sentencia (es decir, una ficción procesal), sino como una auténtica y verdadera sentencia, al punto que sobre ella recae la cosa juzgada.

b) Allanamiento y reconocimiento. EI CPC distingue entre allanamiento y reconocimiento. En el primero el demandado acepta la pretensión y, en el segundo, además de aceptar la pretensión, "admite la veracidad de los hechos expuestos en la demanda y los fundamentos jurídicos de esta" (artículo 330 del CPC). Esta diferencia, sin embargo, parecería bastante artificial: si la pretensión está compuesta por el pedido y la causa de pedir(18), aceptarla (allanarse) significa declarar los hechos son ciertos y, por tanto, el demandante sí tiene razón en lo que pide. Por ello, admitir la veracidad de los hechos y sus fundamentos jurídicos no es otra cosa que declarar que la causa de pedir es cierta. ¿Cuál es, entonces, la diferencia? Desde esta perspectiva, ninguna. Sí habría una diferencia, sin embargo, si, en vez de pretensión, el artículo 330 dijese petitorio o pedido. Ahí se estaría aceptado solamente parte de la pretensión. Y esto parece ser lo que el legislador habría querido decir, puesto que el artículo 322, inciso 3 del CPC, hace la diferencia entre reconocer la demanda y allanarse al petitorio. Lo que interesa aquí, empero, es que, una vez que el juez evalúa el pedido de allanamiento o reconocimiento, "debe expedir sentencia inmediata" (artículo 333 del CPC). Aquí no hay sombra de duda: el allanamiento o reconocimiento conduce a un juicio positivo sobre el mérito de la demanda.

c) Transacción judicial. La transacción, al igual que la conciliación, es un negocio jurídico material con efectos procesales, pues tiene relevancia para el proceso. Asimismo, una vez que el juez evalúa la existencia de concesiones recíprocas y que no afecte el orden público y las buenas costumbres (sea lo que quiera significar esto), homologa la transacción mediante resolución. El artículo 337, inciso
2 del CPC, dice que "la transacción que pone fin al proceso tiene la autoridad de cosa juzgada", aunque esto es incorrecto: la cosa juzgada recae sobre la resolución que homologa la transacción y no sobre la propia transacción. Esto es así porque la cosa juzgada solo puede recaer sobre una resolución judicial (específicamente, una sentencia), esto es, sobre un acto jurídico procesal y jamás sobre el acto jurídico material que constituye soporte fáctico de aquel. De cualquier manera, según el artículo 322, inciso 4, la transacción conduce a una conclusión del proceso con declaración sobre el fondo. Se trata, pues, de una sentencia ${ }^{(19)}$.

d) Des is timien to de la pretensión. El desistimiento del proceso implica una declaración del demandante de no continuar con el proceso, solicitando su conclusión. Según el ar tículo 343 del CPC, este desistimiento no afecta la pretensión. Normalmente se da este pedido cuando la demanda se encuentra mal formulada o, también, producto de una negociación extrajudicial. Ya el desistimiento de la pretensión, por el contrario, implica una declaración del demandante en el sentido de que no tiene razón en su demanda. Por ello, según el art. 344, inciso 1 del CPC, "produce los efectos de una demanda infundada con la autoridad de cosa juzgada". Esto no es otra cosa que una auténtica sentencia, concretamente un juicio de mérito negativo. Aquí, sin embargo, se revela una profunda contradicción que es bueno resaltar: el artículo 321, inciso 1 e inciso 6 del CPC, coloca al desistimiento del proceso y de la pretensión como supuestos de conclusión del proceso sin

(18) Cónfer Cavani, 2016: 181 y siguientes.

(19) Cabe resaltar que en la sentencia recaída en el Primer Pleno Casatorio Civil (Exp. No. 1465-2007-Cajamarca), la Corte Suprema decidió equiparar la transacción judicial a la extrajudicial. El voto en minoría, sin embargo, adoptó una posición que, a mi juicio, es la correcta. 
Renzo Cavani

declaración sobre el fondo. La resolución que aprueba el desistimiento del proceso, dado que no presupone un juicio sobre el mérito, es apenas un auto que, sin pronunciarse sobre el derecho discutido, lo concluye. Pero la resolución que aprueba el desistimiento de la pretensión sí exige un pronunciamiento sobre el mérito y, por tanto, no puede ser un auto, sino una sentencia. El desistimiento de la pretensión, por tanto, debería estar en el listado del artículo 322 del $\mathrm{CPC}$. Empero, en este punto surge una figura misteriosa: la renuncia al derecho (artículo 322, inciso 1 e inciso 5 del $\mathrm{CPC}$ ). ¿Se trata de una figura diferente al desistimiento de la pretensión? Todo parece indicar que no. ¿Por qué? Veamos el artículo 342, inciso 1 del CPC: "El desistimiento del proceso o del acto procesal se interpone antes que la situación procesal que se renuncia haya producido efecto". De hecho, aquí se refiere al desistimiento del acto procesal, pero lo cierto es que desistirse del proceso o de la pretensión también implica renunciar a una situación jurídica: la de ser demandante. Desistirse, por tanto, equivale a renunciar. Para mantener una coherencia en el sistema, por tanto, allí donde el artículo 322, inciso 1 e inciso 5 del CPC, dice renuncia, debería entenderse desistimiento de lapretensión.

\subsection{Autos}

El artículo 121, inciso 2 del CPC, señala:

"Mediante los autos el juez resuelve la admisibilidad o el rechazo de la demanda o de la reconvención, el saneamiento, interrupción, conclusión y las formas de conclusión especial del proceso; el concesorio o denegatorio de los medios impugnatorios, la admisión, improcedencia o modificación de medidas cautelares y las demás decisiones que requieran motivación para su pronunciamiento".

El legislador acierta al momento de ejemplificar algunos tipos de autos (pues hay muchos más), pero se equivoca al entender que los autos se caracterizarían por ser resoluciones que requieren motivación.

Siguiendo la propuesta dogmática ahora planteada, los autos son resoluciones con contenido decisorio que no son sentencias. Toda resolución que contenga un juicio de mérito sobre la pretensión planteada en la demanda pone fin a la instancia: por ello, califica automáticamente como sentencia. Según el esquema del CPC, mediante un auto se puede poner fin a la instancia, pero no mediante un pronunciamiento sobre el fondo. El auto, pues, no resuelve una cuestión de mérito sino una cuestión procesal. Piénsese en los siguientes ejemplos: la resolución que declara improcedente la demanda, sea o no liminarmente; la resolución que estima una excepción (artículo 451, inciso 5 del CPC); la resolución que aprueba el desistimiento del proceso (artículo 343 del CPC); la que declara el abandono del proceso (artículo 346 y siguientes del CPC), etcétera.

Asimismo, existen autos intermedios (Ariano 2015, 76), caracterizados porque a través de ellos se decide cuestiones procesales a lo largo del proceso. Además de las resoluciones mencionadas en el artículo 121, inciso 2 del CPC (saneamiento, interrupción del proceso, concesorio o denegatorio de un recurso, admisión, improcedencia o modificación de medidas cautelares), tenemos: la resolución que admite o rechaza un medio probatorio extemporáneo (artículo 429 del CPC); la resolución que aprueba la modificación o ampliación de la demanda (artículo 428 del CPC); la resolución que ordena una prueba de oficio (artículo 194 del CPC); la resolución que declara la rebeldía del demandado (artículo 458 del CPC); la resolución que se pronuncia sobre un pedido de nulidad (artículo 177 del CPC); la resolución que decreta, vía impugnación, la nulidad de la sentencia o de parte del procedimiento (artículo 121, inciso 3, in fine del CPC), etcétera.

EI CPC, por tanto, se equivoca cuando entiende que la característica del auto es que exige motivación. Como se ha visto, la resolución que exige motivación es, estrictamente, toda aquella que posee contenido decisorio. Entonces, para evitar un razonamiento circular ${ }^{(20)}$, la caracterización de

(20) El cual consistiría en lo siguiente: "la resolución con contenido decisorio es aquella que debe motivarse, mientras que la resolución que debe motivarse es aquella con contenido decisorio". 


\section{¿Qué es una resolución judicial? Un breve estudio analítico para el derecho procesal civil peruano What is a judicial decision? A brief analytic study for Peruvian civil procedural law}

los autos no puede residir en la exigencia de la motivación. La motivación (o, mejor, justificación), más bien, es una exigencia para aquellas resoluciones con contenido decisorio porque se está resolviendo alguna cuestión (procesal) pedida por la parte o de oficio.

Los problemas prácticos de este equívoco surgen cuando un juez entiende que no debe motivar algún pedido de una parte y, por tanto, concluye que no debe expedir un auto sino simplemente un decreto ${ }^{(21)}$. Por ello, no justifica. Pero el razonamiento es equivocado: el juez no debe determinar si es que debe motivar o no, sino, en realidad, si es que debe o no decidir algo según lo que se le ha pedido. A partir que entienda que debe decidir algo, entonces lo decide (sea declarando improcedente, fundado o infundado el pedido) y justifica su decisión.

Inclusive, no es poco común en la práctica encontrarnos con respuestas muy típicas cuando el juez entiende que una parte está pidiendo algo que ya se habría resuelto y, de ahí, emite una resolución con el siguiente tenor: Estese a lo resuelto en la resolución $X$. También ello es usual cuando, a criterio del juez, no es el momento oportuno para solicitarse: Pídase en la oportunidad que corresponda. Esto es un grave error: el juez, dado que está decidiendo algo, debe cuando menos motivar porqué el pedido de la parte sería improcedente.

\section{Resoluciones dentro de una resolución}

Si es que el objeto de impugnación es, fundamentalmente, decisiones, queda claro que puede haber varias decisiones en una resolución-acto, y, a su vez, varias resolucionesacto, dentro de una misma resolución-documento. Podría perfectamente darse el caso, por tanto, que coexistan decretos, autos e, inclusive, una sentencia. Entonces, para saber cómo impugnar no solo es suficiente identificar adecuadamente el extremo de la resolución sino, también, cuáles son las resoluciones que el juez, por un tema de concentración de actos procesales u otra razón, ha emitido en un mismo documento.
Veamos un caso que se ha presentado en la práctica judicial peruana ${ }^{(22) \text { : }}$

Luego de ser notificado con una demanda ejecutiva, el ejecutado deduce la excepción de prescripción y formula contradicción, alegando que había realizado diversos pagos y que el monto objeto de ejecución no es correcto. El juez declaró infundada la excepción y, con base en el art. 690-D, último párrafo, CPC, advirtiendo que la contradicción no se encuadra en ninguna de las causales del mismo art. 690-D, incisos 1 al 3 (inexigibilidad, iliquidez 0 extinción de la obligación, nulidad formal, falsedad o defecto en el llenado del título), resolvió rechazar liminarmente la contradicción.

Aquí, pues, tenemos dos autos: el que se pronunció sobre la excepción y el que rechazó liminarmente la contradicción. Son dos pronunciamientos respondiendo a dos cuestiones diferentes suscitadas por el ejecutado: la existencia de prescripción de pretensión material y la alegación de pluspetición. Pero no solo ello: el art. 690D señala que la decisión que rechaza liminarmente la contradicción es apelable sin efecto suspensivo, mientras que el art. 691, CPC dispone que la decisión que resuelve la contradicción, poniendo fin al proceso único de ejecución, es apelable con efecto suspensivo. Si por "poner fin al proceso único de ejecución" se entiende que la hipótesis solo es aquella decisión que declara fundada la contradicción (dando la razón al ejecutado), entonces, para la hipótesis en donde se declara infundada la contradicción tendría que aplicarse el régimen general, concretamente la norma contenida en el art. 372, segundo párrafo, CPC, que

(21) Esto ya ha sido bien cuestionado por Zavaleta, 2014: 402 y siguientes.

(22) Estos casos han ocurrido en la vida real, pero, por un asunto de confidencialidad profesional, no es posible divulgar los datos del expediente. 
Renzo Cavani

dispone que si la ley no hace referencia expresa al efecto con que se concede el recurso de apelación, deberá ser sin efecto suspensivo (y sin la calidad de diferida).

En nuestro caso, el ejecutante formuló apelación contra ambas decisiones y el juez decidió otorgar efecto suspensivo, entendiendo que al declarar infundada la excepción se pone fin al proceso único de ejecución, sin perjuicio de la eventual ejecución forzada (que, según él, sería un nuevo procedimiento). Más allá del tema interpretativo, lo interesante aquí es advertir que debe distinguirse cada una de las decisiones para determinar, con rigurosidad, cuál es el régimen de apelación aplicable ${ }^{(23)}$.

Las consideraciones expuestas a lo largo de este trabajo también sirven para otras materias, tales como el proceso penal y el proceso laboral, teniendo en cuenta que ambas, al menos dogmáticamente, se nutren del derecho procesal civil. Al respecto, veamos dos casos reales.

El artículo 353, inciso 1 del CPP, dice: "Resueltas las cuestiones planteadas, el juez dictará el auto de enjuiciamiento. Dicha resolución no es recurrible". Las cuestiones a las que se refiere este artículo están detalladas en el artículo 352 del CPP. Una de dichas cuestiones es la estimación o desestimación de las excepciones y la admisión o rechazo de los medios de prueba. Pues bien: en la propia audiencia, una vez expuestos los fundamentos de las partes, imaginemos que el juez desestima alguna excepción planteada por la defensa y rechaza un medio probatorio ofrecido por ella. En la misma resolución emite el auto de enjuiciamiento. Cuando menos aquí tenemos tres extremos:

a) El auto que declara infundada la excepción.

b) El auto que rechaza el medio de prueba.

c) El auto de enjuiciamiento.

Pues bien, cuando el artículo 353, inciso 1 del CPP señala que el auto de enjuiciamiento es inimpugnable, ¿a qué se refiere? Únicamente a la decisión de llevar a juicio oral al acusado, pero no a las otras decisiones, que sí son plenamente impugnables, de conformidad con los ar tículos 404 y siguientes del CPP. Si esto no se entiende adecuadamente podría incurrirse en el grave equívoco de que el juez que expide el auto de enjuiciamiento entienda que es inimpugnable la resolución que declaró infundada la excepción propuesta por la defensa, vulnerando con ello el derecho de defensa. Corresponde, por tanto, formar cuaderno de apelación y, dado que se decretó el auto de enjuiciamiento, continuar con el trámite del proceso.

Finalmente, veamos un caso del proceso laboral regulado por la nueva Ley Procesal de Trabajo (en adelante, "NLPT" o "Ley 29497").

El proceso laboral es un proceso sumamente concentrado, al punto que, al momento de sentenciar, el juez resuelve también sobre las cuestiones procesales y de mérito planteadas por las par tes a lo largo del proceso. En efecto, el artículo 31, inciso 2 de la NLPT, señala: "La sentencia se pronuncia sobre todas las articulaciones o medios de defensa propuestos por las partes y sobre la demanda, en caso de que la declare fundada, total o parcialmente, indicando los derechos reconocidos, así como las prestaciones que debe cumplir el demandado". Si se trata de defensas procesales (esto es, defensas planteadas por el demandado ofreciendo argumentos para que la demanda sea declarada improcedente), el demandado debe plantearlas en su contestación (artículo 19, inciso 2 de la NLPT), la cual debe ser oralizada en la audiencia de conciliación (artículos 42 y 43 de la NLPT) tratándose del proceso ordinario laboral, o en la audiencia única, tratándose del proceso abreviado laboral (artículos 48 y 49 de la NLPT).

Para lo que aquí interesa, en la resolución que pone fin a la instancia, el juez resuelve las defensas procesales (juicio de procedencia). Si es que las declara fundadas (juicio de procedencia positivo) declara la improcedencia de la demanda y la conclusión del proceso; en

(23) Sobre el asunto, con provecho, Cónfer Ariano, 2015: 225 y siguientes. 


\section{¿Qué es una resolución judicial? Un breve estudio analítico para el derecho procesal civil peruano What is a judicial decision? A brief analytic study for Peruvian civil procedural law}

cambio, si las rechaza (juicio de procedencia negativo), emitirá sentencia.

En este caso, el demandado planteó la excepción de convenio arbitral, pero esta es declarada infundada y, acto seguido, se estima la demanda (juicio de mérito positivo). Aquí tenemos, pues, cuando menos dos decisiones: un auto que rechaza la excepción y la sentencia, declarando fundada la demanda.

Luego de la apelación, la Sala Laboral confirmó la resolución de primera instancia. Estrictamente, está confirmando ambas decisiones (extremos). El demandado, no conforme, plantea recurso de casación atacando ambas decisiones, pero solamente diciendo que ataca la sentencia. La Corte Suprema no reparó en el detalle técnico y calificó positivamente el recurso. Empero, aquí tenemos el artículo 35, inciso 1, inciso 1 de la NLPT, que dice lo siguiente: "El recurso de casación se interpone (...) contra las sentencias y autos expedidos por las salas superiores que, como órganos de segundo grado, ponen fin al proceso» (similar redacción tiene, por cierto, el artículo 387, numeral 1, inciso 1 del CPC). En nuestro caso, por tanto, solo cabe impugnar la sentencia, pero no el auto que desestimó la excepción de convenio arbitral. ¿Por qué? Porque dicho auto no pone fin al proceso. Esto quiere decir que la Corte Suprema no puede ni debe pronunciarse sobre el convenio arbitral: esta resolución ya quedó firme. Lo que corresponde apenas es determinar si la sentencia es fundada o no. Esto quiere decir que solo puede evaluar el juicio positivo sobre el mérito, pero ya no el juicio de procedencia.

Si esto no se entiende adecuadamente, podría incurrirse en el grave equívoco de que la Suprema revoque el auto que declaró infundada la excepción de convenio arbitral y, por tanto, declare improcedente la demanda (como, en efecto, ocurrió en el caso real).

\section{Conclusiones}

Entender adecuadamente el concepto de decisión y resolución judicial es determinante para realizar una adecuada tipología de las diversas especies de resoluciones judiciales reguladas en el CPC. Asimismo, diferenciar entre resolución-documento y resoluciónacto, muestra que la identificación de esta contenidas sirve para delimitar qué puede ser objeto de la impugnación, sobre todo frente a las normas recursales que establecen el recurso adecuado y aquellas que restringen la competencia de los órganos jurisdiccional para conocer ciertos pronunciamientos.

Finalmente, identificar que lo que se impugna sería, rigurosamente, la decisión (como conclusión del razonamiento) contenida en el acto, sirve para entrelazar el discurso del procesalista con la teoría de la argumentación jurídica, al punto de advertir la importancia de esta al momento de construir la pretensión recursal que cuestionará el razonamiento judicial(24).

\section{Referencias bibliográficas}

Almedia, Diogo Assumpção Rezende de. 2015. A contratualização do processo - Das convenções processuais no processo civil de acordo com o novo CPC. São Paulo: LTr.

Assis, Araken de. 2015. Direito processual civil brasileiro, vol. III - Par te especial:

(24) Queda pendiente, pues, para un futuro trabajo, recurrir nuevamente a las contribuciones de la teoría de la argumentación jurídica para dotar de un contenido normativo más preciso las exigencias del CPC consistentes, respecto de las disposiciones generales sobre los medios impugnatorios, en "fundamentar el pedido (recursal)" (artículo 358 del CPC), "precisar el agravio y el error" (artículo 358 del CPC); respecto del recurso de apelación, "indicar el error de hecho o de derecho incurrido en la resolución" (artículo 366 del CPC), "sustentar su pretensión impugnatoria" (artículo 366 del CPC); y, respecto del recurso de casación, "sustentar el recurso en la infracción normativa que incida directamente sobre la decisión contenida en la resolución impugnada o en el apartamiento inmotivado del precedente judicial" (artículo 386 del CPC), "describir con claridad y precisión la infracción normativa o el apartamiento del precedente judicial" (artículo 388 inciso 2 del CPC) y "demostrar la incidencia directa de la infracción sobre la decisión impugnada" (artículo 388 del CPC). 


\section{Renzo Cavani}

procedimento comum (da demanda à coisa julgada). São Paulo: Revista dos Tribunais.

Ariano, Eugenia. 2015. Impugnaciones procesales. Lima: Instituto Pacífico.

Ataíde, Jr., Jaldemiro Rodrigues de. 2015. Negócios jurídicos materiais e processuais - existência, validade e eficácia Campo invariável e campos dependentes: sobre os limites dos negócios jurídicos processuais. Revista de Processo, vol. 244: 393-423.

Atienza, Manuel. 2013. Curso de argumentación jurídica. Madrid: Trotta.

Cabral, Antonio do Passo. 2016. Convenções processuais. Salvador: JusPodivm.

Cabral, Antonio do Passo y Pedro Henrique Nogueira, coords. 2017. Negócios processuais (2015), $3^{\underline{a}}$ ed. Salvador: JusPodivm.

Calmon de Passos, José Joaquim. 2009. Esboço de uma teoria das nulidades aplicadas às nulidades processuais (2002), $1^{1}$ a ed. Forense: Río de Janeiro.

Cavani, Renzo. 2014. La nulidad en el proceso civil. Lima: Palestra.

2015. "Decisión justa": ¿mero slogan? Por una teorización de la decisión judicial para el proceso civil contemporáneo. Justicia 1: 335-83.

2016. "Fijación de puntos controvertidos": una guía para jueces y árbitros. Revista de la Maestría en Derecho Procesal de la PUCP, vol. 6 (2): 179-200.

Carnelutti, Francesco. 1930. Sistema del diritto processuale civile, II - Atti del processo. Padua: Cedam.

Chiassoni, Pierluigi. 2007. Tecnica dellinterpretazione giuridica. Bologna: II Mulino.

Conso, Giovanni. 1955. I fatti giuridici processuali penali. Milán: Giuffrè.
Costa, Adriano Soares da. 2017. Para uma teoria do fato jurídico processual. Revista de Processo, vol. 270: 19-56.

Denti, $\mathrm{V}$ it tor io. 1965 . Nullit à degli at ti processuali civili. Novissimo Digesto Italiano, XI: 467-86.

Didier Jr., Fredie. 2015. Curso de direito processual civil, vol. 1 - Introdução ao direito processual civil, parte geral e processo de conhecimento, 17aㅡ ed. Salvador: JusPodivm.

Didier Jr., Fredie, Paula Sarno Braga y Rafael Oliveira. 2015. Curso de direito processual civil, vol. 2 - Teoria da prova, direito probatório, decisão, precedente, coisa julgada e tutela provisória, 10ª ed. Salvador: JusPodivm.

Didier Jr., Fredie y Leonardo Carneiro Da Cunha. 2016. Curso de direito processual civil, vol. 3 - Meios de impugnação às decisões judiciais e processo nos tribunais (2006), $13^{\mathrm{a}}$ ed. Salvador: JusPodivm.

Didier Jr., Fredie y Pedro Henrique Nogueira. 2011. Teoria dos fatos jurídicos processuais, 1a ed. Salvador: JusPodivm.

Domir, Otávio Augusto dal Molin. 2016. Iura novit Curia e causa de pedir - $O$ juiz e a qualificação jurídica dos fatos no processo civil brasileiro. São Paulo: Revista dos Tribunais.

Guastini, Riccardo. 2011. Interpretare e argomentare. Milán: Giuffrè.

Mello, Marcos Bernardes de. 2014. Teoria do fato jurídico. Plano da existência (1985), $20^{\mathrm{a}}$ ed. São Paulo: Saraiva.

Monroy Palacios, Juan José. 2005. Admisibilidad, procedencia y fundabilidad en el ordenamiento procesal civil peruano. Jus Doctrina \& Práctica 5: 185-97. 
¿Qué es una resolución judicial? Un breve estudio analítico para el derecho procesal civil peruano What is a judicial decision? A brief analytic study for Peruvian civil procedural law

Nogueira, Pedro Henrique. 2016. Negócios jurídicos processuais. Salvador: JusPodivm.

Nogueira, Pedro Henrique y Renzo Cavani, coords. 2015. Convenciones procesales - Estudios sobre negocio jurídico y proceso. Lima: Raguel.

Pannain, Remo. 1933. Le sanzioni degli atti processuali penali - Nullità - Preclusioni - Decadenze - Inammissibilità. Nápoles: Jovene.
Pontes de Miranda, Francisco Cavalcanti. 1970. Tratado de direito privado [1954], tom. II. Río de Janeiro: Borsói.

Redenti, Enrico. 1959. Atti processuali. a) Diritto processuale civile. Enciclopedia del diritto, IV: 105-40

Tucci, José Rogério Cruz e. 2009. A causa petendi no processo civil (1993), 3aㅡ ed. São Paulo: Revista dos Tribunais.

Zavaleta, Roger. 2014. La motivación de las resoluciones judiciales como argumentación jurídica. Lima: Grijley.

\section{Rebaza, Alcázan \& De Las Casas}

Fusiones y Adquilsiciones

Reestructuración y Quiebras

Financiamientos

Mercado de Capitales

Proyectos e Infraestructura

Inversión Exranjera

Asesoria Corporativa

Planificación Tributaria
Planificación Laboral

White Collar Crime

Litigios Corporativos

Arbitraje

Private Clients

Venture Capital

Compliance

Perú Client Service Award 2016 - Chambers and Partners Awards for Excellence
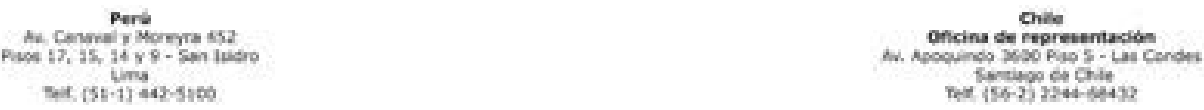

www,rebaza-alcazar.com 